\title{
Infusing African Heritage into a Canadian Curriculum
}

\author{
Maureen Finlayson, \\ Teacher Education, Cape Breton University, Canada
}

\begin{abstract}
There is a richness of diverse cultures in present day society. Each culture has a specific history, heritage and traditions which should be maintained and passed on to future generations. In fact, many cultures are not present in mainstream education. Students need to be connected to their own experiences and to see themselves in the resources, and curricula of the classroom. However, there is a lack of African heritage in the curriculum in Nova Scotia public education. To address this need a course entitled English 12: African Heritage language arts was created. Interviews were conducted with educators who designed, developed and implemented this course. This study examines the process involved, the challenges and successful strategies employed by these educators. The author suggests that the implementation of English 12: African Heritage language arts has positive implications for all educators and students in their intercultural understanding and teaching and learning methodologies.
\end{abstract}

\section{Introduction}

Engaging students in learning is a challenge in today's educational systems. To be engaged, students need to be connected to their own experiences and to see themselves in the resources, and curricula of the classroom. Students learn by making connections. To make connections, students need to have access to resources which support their culture and heritage. However, the resources of many cultures, most specifically the African Canadian culture, are not always present in mainstream education.

This paper is designed to address the lack of African heritage in the curricula and resources of Canadian schools in Atlantic Canada. As a result, all students are unaware of the history and positive contributions of African Canadians to community and society. In fact, very few African Canadian students graduate from high school, and from those who do graduate, very few continue on to post secondary studies. As a result, the positive contributions of these students to community and society are never fully achieved. Furthermore, in the workplace, employers often comment that many students are unable to function effectively in the workplace, and are ill-prepared for collaborative problem-solving and decision-making, intercultural environments of the 21 st century.

Two research projects inform this research. In the first project, ten African Canadian educators in Nova Scotia were interviewed to determine the obstacles and challenges which they faced in the school system (Finlayson, [12]). One challenge which they all identified was the lack of African heritage in the curriculum in Nova Scotia public education.

This lack of African heritage in the curriculum has been addressed by the Nova Scotia Department of Education in a very concrete way. In 2008, the curriculum consultant of the African Canadian Services Division of the Department of Education organized a lead team to discuss, prepare and launch a new course: English 12 African Heritage language arts (Finlayson, [11]). This was a recommendation of the BLAC report [1]. The purpose was to give students an opportunity to complete a grade 12 English language arts credit with a focus on African heritage. This course has the same credit value as Academic English 12, the same curriculum outcomes, and can be taken as the required English language arts credit for high school graduation and for acceptance to university.

In this article, there is a focus on the second research project: the development and implementation of the English 12: African Heritage language arts course. Teachers of the English 12 African heritage language arts course were interviewed to determine the challenges and successes they have had in designing, developing and implementing this course. This article provides an overview of English 12: African Heritage Language Arts course, and addresses the challenges and successes as presented by the educators who teach English 12: African heritage language arts. Through the process, African Canadian students and mainstream students have been actively engaged in the process of learning.

\section{Research Rationale}

African Canadian students face unique challenges in education. A primary concern has been the absence of African Canadian history and literature in their learning resources (Dei [7]; Brathwaite \&James [7]).

There is a growing need to rethink curriculum in terms of the cultural needs of an increasingly diverse population. There is range of knowledge that may be 
out of reach for a person to learn on their own, but is accessible if the learner has the support of peers or more knowledgeable others (Vygotsky, [19]; Forman, E.A. \& J. McPhail, J., [13]).

Scholars in this field have documented that teachers are more effective when they provide cultural connections to the curriculum, draw on student cultures in their teaching styles and address the struggles that their students face (Bennett [3]; Dei [8]: Dickar [9]; Delpit, [10]). Black teachers are ideally positioned to enrich the curriculum with cultural and cognitive strategies that led to greater success in schools by students of color (Cummins, [6]; Gill, [14]). They enriched the curriculum content, sharing stories and singing songs, sharing their own cultural knowledge and teaching students about cultural traditions. As clearly stated: "They made sure that curriculum materials reflected a multicultural and antiracist perspective, searched for learning materials with diverse representation, and screened for stereotypes and bias" (Solomon, [18]:403). In their research, Carr and Klassen emphasize that, "the attitude of the teacher is crucial in helping students develop attitudes that will prepare them for a harmonious existence in a society that is culturally diverse" (Carr and Klassen, [4]: 69)

I want to contribute to this literature of narrative research by examining the process which Canadian educators have used to create a curriculum with a focus on African Canadian heritage. It is important to know what challenges these educators have faced, and what strategies they have created to overcome these challenges in order to successfully implement an English 12: African Heritage language arts course.

\subsection{Research design and goals}

To gather information from participants, researchers sometimes use focus groups, interviews and survey/questionnaires. The interview process has been used by researchers to elicit information from individuals about various issues. Seidmann [17] has used an interview process to explore the experiences of the participants, their educational experience and their interactions with their colleagues and other members of the communities. This approach allows the researcher to ask open-ended questions to build upon and explore the participants' responses to these questions. The goal is to have the participant recount her/his experiences within the topic under study. This qualitative approach conforms to education research practice and allows the researcher to ask open-ended questions to build upon and explore the participants' responses to these questions.

Interviews were conducted with educators within the educational school system of Nova Scotia. Some educators are of African heritage and others are from mainstream society. All indicated a willingness to participate in interviews. I have selected these individuals as a result of the diversity of their backgrounds and the success which they have had in implementing the course. These individuals all had a passion for African heritage and a determination to succeed. They worked in schools which represented (a) diverse communities; (b) schools from rural and urban areas (c) schools with a large African Canadian population (d) schools with a large Eurocentric population (e) schools with a combination of diverse cultures (f) schools with teachers from diverse races, cultures and backgrounds.

This study reflects the responses of the teachers who have organized, designed, and implemented English 12: African Heritage language arts. The format used is a question and answer approach because it enables me to capture the highlights of the course from each participant. I want to know about the process that was used to design this course and how these teachers were able to be successful. I want to know what challenges they faced and how they were able to overcome these challenges. I want to have a clear understanding of the content of the course and the implications for our students of having a course linked to African heritage as part of the curriculum in public schools.

This article has been organized to provide an overview of the course English 12: African Heritage language arts: the timeline, the learning outcomes and suggested resources. The course content and themes are linked directly to an African heritage focus. The goal of this research is to have the participant recount her/his experiences within the topic under study. Specific questions have guided the data collection and analysis. These questions include:

(1) What process has been used?

(2) What obstacles and challenges have you faced?

(3) What strategies have you used to be successful in the implementation of this course?

The data collected has been compiled into themes of the process, the components of the course, an overview, and responses and strategies of the participants, who successfully addressed many obstacles and challenges.

\section{Participants}

Educators who participated in this study are strongly committed to the infusion of African heritage into the curriculum. All of these educators have been directly involved in selecting the resources, in developing and implementing the English 12: African Heritage language arts course, and in providing a leadership role to offer professional development to other teachers. They had been selected for the development and implementation of English 12: African heritage 
language arts, because of their involvement in the elective: African Heritage Literature which was offered in six schools over a 4 year period. They were recognized for their enthusiasm and creativeness. They were identified as leaders in supporting African heritage in the curriculum, because of their determination to pass on African heritage to all their students

African Canadian educators who participated in this study have been successful. A brief description of each participant follows. As you will see, the participants come from a variety of backgrounds, and teach in schools with diverse populations. Two teachers worked in an urban high school, where students spoke twenty-nine different languages. One of these teachers is African Canadian born in Nova Scotia; the other teacher was married to an African Canadian, originally from Nigeria. Two teachers worked in schools where the students were of Eurocentric descent. These teachers were both very connected to the community, and frequently invited leaders of the African communities to their classrooms to make presentations to their students. Two teachers worked in all White schools. They frequently organized school trips to museums and art galleries, where African heritage was a major focus. One teacher worked in an isolated area, with a small African Canadian population. This teacher emphasized the contributions of all her students and community leaders, in particular the African Canadian contributions. One teacher worked in a school with a large African Canadian population, both student and staff. In this school, the principal is African Canadian, and the school has an active African Canadian welcome center.

Ruth is an African Canadian born in Nova Scotia. She says, "I am a teacher, because I had people in public life and at home who encouraged me to succeed, to live up to my potential". She has taught for many years in classes, and always incorporates African literature in her lesson plans. Ruth insists on students reaching their potential, in order to have the skills they need to pursue their dreams. She teaches in a school with many diverse cultures and languages.

Janice is a mainstream teacher, who works in an isolated area, and who takes a genuine interest in all her students. She strives to get to know her students, to know their backgrounds and cultures, and to make connections with the community. To ensure that her students have a broad knowledge base, she organizes many school trips, bringing her students to art galleries, museums, and educational venues in the city. She teaches a few African Canadian students in each of her classes.

Denise teaches in a rural area. She has a passion and commitment to African heritage. She has been infusing African heritage for years into her curriculum. She has built up a bank of diverse resources which students can draw from. Denise has a love for creative arts. She has her students creating collages, sculptures, carvings, etc. with the African heritage focus. Denise has a web site which is well maintained and which presents these creative works of her students. Denise also invites high profile African speakers to her classes to motivate her students.

Nancy has been teaching in the same school for about 15 years. When she was given the opportunity to get involved with developing English 12: African heritage, she jumped at the chance. She wanted a change in direction, and this course provided her with a new focus. Her students really excelled with her teaching style and her devotion to her work. Whenever Nancy could have African Canadian artists join her class, she did so, for the benefit of all her students.

David worked with small numbers of students in the resource learning center. He was thrilled to be part of the process of developing and implementing this course. He took advantage of the different activities, both in technology and in art, to respond to the diverse needs of his small group. David's enthusiasm rolled over into his classes, giving his students new motivation and new ideas.

Marilyn worked in a relatively new school with the latest software and technology. Marilyn saw the development and implementation of this course as an opportunity to produce audio visual creations and videos. Marilyn invited a well know African Canadian film maker to come and train her students. This was an experience, which all of her students talked about enthusiastically.

\section{Findings}

Based on the data analysis of the interviews, participants identified the process, basic components, overview and challenges and strategies for success.

\subsection{Process}

The dialogue began by asking if African heritage was part of the curriculum which they used and how it was incorporated into the programs which they taught.

How do you incorporate African heritage into the English Language Arts curriculum?

African heritage is incorporated into the curriculum at all levels by resources which reflect African heritage, and by teachers committed to select themes of African heritage. In some cases, African heritage is well incorporated depending on the knowledge and commitment of the teacher providing the leadership. In other cases, there is little or no incorporation of African heritage into the curriculum. 
Do you have any specific courses that focus directly with African heritage?

Yes, we do. At the secondary level, English 12: African Heritage language arts and African Canadian Studies 11 have been developed and implemented in the schools of Nova Scotia.

Can you provide me with specific information on the course English 12: African Heritage language arts, the status, etc?

English 12: African Heritage (E12:AH) was created in 2008 (Finlayson [11]). It has the same credit value as academic English 12. It is listed in the Department of Education documents, and in all school calendars. It can be taken as a graduation requirement, or for requirements for university acceptance.

What is its purpose?

Its purpose is to provide students in Nova Scotia with the opportunity to learn English, by using resources either written by authors of African heritage, or writings with a focus of African heritage. Why was English 12: African Heritage created?

This was a recommendation of the BLAC report [1]. The Black Learners Advisory Report (BLAC) was published in 1994 by the Black Learners Advisory Committee, as a result of information gathered from surveys, questionnaires and conversations with members of Black communities across Nova Scotia. The BLAC report made several recommendations to support the education of African Nova Scotians. These included: the establishment of the Council of African Canadian Education(CACE); the establishment of the African Canadian Services Division at the Nova Scotia Department of Education; the establishment of scholarships, to be supported by government funds, and used to support Black learners for post secondary education; the establishment and maintenance of $\mathrm{RCH}$ coordinators in all school boards; the provision of Support Workers for Black learners in schools; the creation and implementation of anti-racism policies; the infusion of African heritage into the curriculum through a variety of resources, the creation of courses, and by the process of providing professional development to teachers and administrators, etc. What is African Canadian Services Division?

The Nova Scotia Department of Education has several divisions to develop programs and resources, to provide leadership in professional development and to provide support for teachers across Nova Scotia. These divisions include: African Canadian Services Division, Acadian Services, English Programs, French Second Language Programs, Student Services, Learning Resources and Technology, Evaluation and Assessment. The African Canadian Services Division (ACSD) was established in 1996, as a recommendation of the BLAC report. The goal of ACSD is to ensure that African heritage be an integral part of all elements of the programs, in the resources, in professional development, in the development and delivery of all curricula, and in the support of Black teachers and in the recruitment of African Canadians into educational careers. English 12: African Heritage was developed by the African Canadian Services Division.

How was English 12: African Heritage developed?

The African Canadian Services Division made the decision to provide the resources (human and written) and financial commitment to develop and implement a language arts course with an African heritage focus. A curriculum consultant was hired by the African Canadian Services Division. Her responsibility was to develop the curriculum for this course, to gather together a lead team to plan the course and collect the resources, and to organize and plan professional development. A lead team was selected from English teachers across Nova Scotia who had demonstrated a commitment to incorporating African heritage into the curriculum and who used innovative teaching practices. This lead team consisted of 12 individuals, who designed the course, decided upon the resources which were to be used, and piloted the course over a two year time frame. At the end of this period, recommendations and changes were made. Professional development was organized and led by this lead team, provided lesson plans, teaching and learning strategies, and hands on activities to enable teachers, principals, and guidance counselors to become familiar with the content and purpose. These sessions were open to all educators who were interested, and were delivered in a number of locations across the province, providing educators easy access.

Has this course been well received?

It has been very well received. Students who have taken this course speak of the variety of teaching and learning styles incorporated in the course, and the benefits of studying these diverse topics. They indicated how discussions were encouraged with regard to social justice: how to address discrimination and racism; creating and sharing strategies of resistance. The students spoke of how well this course prepares them to live in our intercultural world and to become global citizens. If a teacher is not familiar with the resources, how can he/she find out what resources to use?

Resources have been carefully selected for each unit. Resources include the titles of books, articles, audio cd's, dvd's, websites, posters. Resources have been purchased and placed in schools across Nova Scotia. If a teacher wants to borrow cd's or dvd's, he/she can contact the Department of Education of Nova Scotia for borrowing. 


\subsection{Basic Components}

What are the components of this course?

E12:AH has the same outcomes as English 12.

The course has been carefully designed with an overview, a timeline, and a focus on the following themes: Pre-Colonial Africa, Slavery, Reconstruction, Harlem Renaissance, Social and Political Change, Contemporary Literature including Black Women Writings.

What are some of the resources?

In many ways the course follows a historical timeline, so that new knowledge can be introduced and linked to previous knowledge, in a cyclical manner. It is suggested the teacher begin with historical and geographical information of Africa, to provide students with the background they will need to discuss the issues which emerge in the units.

Resources for the beginning unit Pre-Colonial Africa include: Things Fall Apart by Chinua Achebe; oral histories and traditions; poetry by Diop, Maxine Tynes and Shauntay Grant; pre-colonial and contemporary maps of Africa; fables and folktales of Africa, etc. Other resources include slave narratives; spirituals and speeches; writings of Frederick Douglass, W. DuBois, Biko, Martin Luther King, Nelson Mandela; Jim Crow laws; fine arts of the Harlem Renaissance; contemporary Black literature including the writings of Black women and men. Several websites have also been identified to support all these units.

Has integrating the arts been a component of this course?

In fact, yes it was. The curriculum consultant for the African Canadian Services Division worked with the Art Gallery of Nova Scotia to set up ArtsSmarts projects around the province. Her role was to ensure that the curriculum outcomes were being implemented and to identify the school and teacher for this project. The Art Gallery and the African Canadian Services Division shared the cost. The Art Gallery consultant contacted a Black artist in the school region and set up the initial meeting. At this meeting, representatives from ACSD, the Art Gallery, the artist, and the teacher determined what the art project would be, and purchased the art supplies. It was a fabulous idea. Several art projects were implemented around the province. It was a wonderful opportunity for the students, the school and the community. Students employed several innovative ways to represent their ideas and to demonstrate their potential. Some involved visual arts, drama, music, the spoken word, etc. In fact, the Art Gallery had an exhibit of some of the art work, and had an official presentation of the drama and the spoken word.

Has integrating technology been part of this course?

Technology has been integrated throughout the course. A professional learning community was created at the African Canadian Services Division to support the teachers during the implementation stage. Teaching and learning strategies include the use of web sites for the accumulation and sharing of knowledge; the use of technology for the development of projects, games, and learning activities, etc.

\subsection{Overview}

What would be a brief overview of this course?

English 12: African Heritage Language Arts is based on the framework provided by the Atlantic Canada essential graduation learnings and the Foundation for the Atlantic Canada English Language Arts Curriculum. This curriculum is shaped by the vision of enabling and encouraging students to become reflective, articulate, and literate individuals who use language successfully for learning and communicating in personal and public contexts. English 12: African Heritage Language Arts focuses on African heritage, and encourages the use of diverse resources from all cultures and races. It involves language processes and supports language learning outcomes: speaking, listening, reading, viewing, writing and other ways of representing.

This course focuses on writers and artists of African descent and their contributions. It encompasses the experience, study, appreciation of language, literature, media, and communication from an African heritage perspective. To present this course, a teacher may follow a linear timeline, or study texts from a thematic approach. It is critical that the students become aware of the historical context of the texts. The historical timeline would be: pre-colonial Africa, slavery and resistance, reconstruction, renaissance, and contemporary literature. Some of the themes include: social and political change, women's movement, visual and performing arts, and the lives and experienced of African Canadians and African Nova Scotians. This course helps students to understand and appreciate that African heritage as being a heritage of us all.

A study of Chinua Achebe's novel Things Fall Apart is fundamental for the course. This novel offers an example of a community in Nigeria that demonstrates the sophistication of pre-colonial Africa. From interacting with the ideas and concepts of this novel, students explore the diversity of Africa, the different regions, cultures, languages, and traditions. In the discussion, students are provided with an opportunity to challenge some of the stereotypes that exist about Africa. They learn that Africa is a continent with a rich history, and distinct social, political, spiritual and legal systems. This provides a foundation to enable students to connect with people of African descent today, and to determine how these historical elements have influenced all cultures and histories. 
Information and themes addressed in pre-colonial Africa include: Afrocentrism; geographic and cultural diversity; the role of the family and the village; relationships; spirituality; the influence of Arab and Islam culture; folklore; proverbs; pride; the importance of names; animal imagery; and female expression. It is important that the concept of Afrocentricity be introduced in the early stages of the course. Afrocenctricity is defined in the following manner:

Afrocentric, Africentric, or African centered, are interchangeable terms representing the concept which categorizes a quality of thought and practice, which is rooted in the cultural image and interest of African people and which represents and reflects the life experiences and traditions of African people as the center of analysis. African centered study looks at any information involving African people and raises questions that allows African to be subjects of historical experiences rather than objects on the fringes of another's experiences.

(MolefiAsante:http://www.afrocentric.info/African Centered/Definitions.html)

Students learn about the African world view, examine the Afrocentric concept within oral traditions, and later in the works of contemporary African writers and writings about African heritage.

Students study slavery and the Middle Passage. As they study about the horrific circumstances of this period, they are also be exposed to the ways that African slaves entered into resistance. Analyzing the beginning of slavery and the resistance of those enslaved helps to dispel the myth that African hostages accepted slavery passively. This study provides the foundation for many of the concepts which is studied throughout this course: slave narratives, poetry, spirituals, the African Diaspora. Students learn that along with their struggles emerged leaders who became role models: Frederick Douglass, Sojourner Truth, Bullwhip, Olaudah Equiano, etc. Students study the global struggles for freedom and the political, social, educational and economic barriers to enter mainstream society. Equity, equality, and critical literacy become important components of their learning.

Although students are exposed to the periods of Reconstruction and Harlem Renaissance of the United States, they learn how Canada has had a different cultural history. Canada's Renaissance began in the late seventies and eighties with a proliferation of African Canadian writers, who through their writings, reflect their diversities of experiences, backgrounds and genres. Whereas in the United States, Black literature is seen as a body of work, in Canada it is viewed as individual works.

African heritage writings are linked to a history of protest and social change. Black writers have consistently emphasized the desire of Black people to assert themselves as active participants in the larger society, yet being conscious of the support and importance of family and community in their lives. The students are given the opportunity to hear the voices of a people who speak and act against racial justice and celebrate their victories, survival, and resilience. The ideas and discussion enable students to become aware of their relevance in the process of social change. Students are exposed to a significant number of global texts, including indigenous local writers, writers from across African and the world.

As the course focuses on the contemporary period, it encompasses numerous themes: Back to African movement, women's movement, other ways of writing through visual and performing arts. The women's movement is given a central place. Black women, expressing dilemmas about their role in the family and society, provide a critical commentary about their particular ideas, experiences, struggles and victories. Women of African descent have been the strength and backbone of the Black family throughout the ages. They have had to redefine their role and position in an ever changing society. Over time, Black women have demanded more power and respect within the family, community, workplace, church and community. In the literature, these relationships have been defined and evaluated. Students study these texts and become more aware of the excellent leadership and role models that Black women have provided.

Visual and Performing Arts is an expression of the self; one's inner thoughts and dreams; a continuum of fantasies from childhood to adulthood. It allows students to explore the dimension of visual and performing arts over time through dialect, characterization, humor, and cultures across the Diaspora. This section allows for examination and study of past and present forms: blues, hip hop, Harlem Renaissance art, contemporary dance and music, etc. through film, video, internet, audio, art, music, technology, and all forms. Through the works of these artists, students connect with the evolution of societies, community life, and immigrant experiences past and present.

A special component of African Heritage Language Arts is the study of a few African Nova Scotian writers and artists. This helps students to develop a greater consciousness of their Nova Scotian heritage and gain the opportunity to see the familiar through different eyes. To hear of one's homeland from one who has a different identify and perspective can be challenging and illuminating.

The English 12: African Heritage Language Arts course has a clear connection to the history and literature from Africa, as well as, from the Diaspora. There is a plethora of material available to engage students and to provide them with opportunities to become critical readers, writers, and thinkers. This course provides them with the opportunity to develop strong critical literacy skills and to have a greater 
understanding of the connection African heritage to the intercultural world and society that we live in.

\subsection{Responses and Strategies}

Has there been any resistance to this course?

There has been resistance when individuals were not informed. In some cases, teachers, guidance counselors and principals did not attend the professional development sessions. As a result of this, they did not receive the information and would sometimes discourage students from taking the course, or simply assume that it was not at the same level as the traditional English courses. As a result, they were giving incorrect information to students and parents.

What has been the response of lead teachers who have implemented this course?

Nancy explained:

I have been teaching for about 15 years, the same course, the same material. Receiving these resources, and teaching this course has given me new life. I want to get up and go to teach, I have had such good response from my students.

Ruth said:

I have several Black students in my class. They were always asking me for materials and writings by authors of African heritage. This has been a godsend. Now I have all the resources that I need. When students want to discuss social justice issues, or situations of discrimination or racism, we have the time and the space to do this. It is an excellent course.

Denise commented:

I work in a school with an all White population. Students have no understanding of some of the challenges and obstacles Black students face. Here is a course which gives us the opportunity to discuss these issues and be open to new ideas.

Janice responded:

We live in a multicultural and ethnically diverse world. I need to prepare my students to live and work in this world. This helps me to prepare my students to live in a global society and to learn how to interact with individuals of various ethnic and cultural backgrounds.

David responded:

It used to really annoy me when teachers felt that the only time they had to talk about African heritage was during February. This course gives me the opportunity to incorporate African heritage throughout the whole year.
Marilyn said:

I had one Black student in my class. Whenever an issue arose re African heritage, I used to turn to her and expect her to know all about it. How wrong I have been, it is my responsibility to be informed and to teach her of African heritage, as I would teach any of my students about their heritage.

\section{Conclusion}

In this intercultural world in which we live, we can no longer be lacking in knowledge or understanding of diverse cultures and how these function together to create who we are. In Canada, knowing and understanding African Canadian heritage is fundamental to our education. Leaders of African Canadian communities have made significant contributions at regional, national and international level. We need to become aware of these contributions and make them an important part of our knowledge base.

In this course, English 12: African Heritage language arts, all students are able to learn the history and traditions of African Canadians, and their ancestors. Through the open dialogue and discussions, they can begin to appreciate the obstacles and challenges which African Canadian students face. African Canadian students can learn about their own history and culture, and take pride in their heritage. Using the resources and learning strategies, all students can acquire the knowledge and skills which they need to be well prepared to be collaborative problem-solvers and creative decision-makers for the intercultural environments of the $21 \mathrm{st}$ century.

This course, English 12: African Heritage was created at a specific historical moment and in a certain place. As Henry indicates, "teaching practices are context specific and culture bound" (Henry, [5]:134). These teachers in Nova Scotia re-shaped their practices to serve the needs of their students. "Discussions of alternative teacher narratives and practices may help broaden the notions of pedagogy and curricula" (Henry, [5]:134), wherever you are.

The infusion of African heritage into the curriculum in Nova Scotia through this course: English 12: African Heritage language arts is a beginning. This course has been carefully developed and implemented by curriculum leaders and educators. The overview in this article provides preliminary information for any educator to begin the process of infusion of African heritage into his/her curriculum wherever he/she teaches. In conclusion, as an educator, I challenge you to create learning 
opportunities for all students to understand the role that African heritage has played in the past, and to make African heritage sustainable in the future.

\section{References}

[1] Black Learners’ Advisory Report. (1994) Halifax, Nova Scotia: Department of Nova Scotia.

[2] Butchart, R. (1998) 'Outthinking and outflanking the owners of the world: a historiography of the African American struggle for education', History of Education Quarterly, 28 (3), 333-336.

[3] Bennett, C. (1995). 'Preparing teachers for cultural diversity and national standard of academic excellence'. Journal of Teacher Education, 46 (4), 259-265.

[4] Carr, P.R., T.R. Klassen. (1997) 'Different perceptions of race in education: racial minority and White teachers', Canadian Journal of Education, 22(1), 67-81.

[5] Codjoe, H.M. (2006) 'The role of an affirmed Black cultural identity and heritage in the academic achievement of African-Canadian students', Intercultural Education, 17(1), 33-54.

[6] Cummins, J. (1986). 'Empowering minority students: A framework for intervention'. Harvard Educational Review, 56 (1) 18-36.

[7] Dei, G. (1996) 'Listening to voices: Developing a Pedagogy of Change from Narratives of AfricanCanadian Students and Parents', in K. Brathwaite \& C. James (eds.) Educating African Canadians, Toronto, Canada: James Lorimer \& Company Ltd.

[8] Dei, G. (2005) 'Racism in Canadian contexts: Exploring public and private issues in the educational system', In W. J. Tettey, \& K. P. Puplampu, (eds.), The African diaspora in Canada: Negotiating identity and belonging, Calgary, AB: The University of Calgary Press.

[9] Dickar, M. (2008) 'Hearing the silenced dialogue: an examination of the impact of teacher race on their experiences', Race Ethnicity and Education, 11 (2), 115-132.

[10] Delpit, L. (1995) Other people's children: Cultural conflict in the classroom. New York: New York Press.

[11] Finlayson, Maureen. (2008). English 12: African Heritage Language Arts Curriculum Document. Halifax, Nova Scotia: Department of Nova Scotia. 81 pages.

[12] Finlayson, Maureen. 2012. 'Exploring unique challenges and successful strategies identified by Black Educators in the Canadian context', Literacy
Information and Computer Education Journal (LICEJ), 3, 2, 592-600.

[13] Forman, E.A. \& McPhail, J. (1993). 'A Vygotskian perspective on children's collaborative problem-solving activities'. In E.A. Forman, N. Minick, \& C.A. Stone (eds.), Contents for learning: Sociocultural dynamics in children's development. New York: Oxford University Press. 213-229.

[14] Gill, W. (1992). 'Helping African American males: The cure'. The Negro Educational Review, 63, 31-36.

[15] Henry, A. (1998). 'Learning form the teaching of African Canadian women: a Reflection for African American Students'. In V.R. D'Oyley \&C.E. James (eds.), Re/visioning: Canadian Perspectives on the Education of Africans in the Late 20th Century. North York, Ontario: Captus Press Inc. 120-138.

[16] Sadlier, R. et al. (2009) Black History: Africa, the Caribbean and the Americas. Toronto, Canada: Emond Montgomery Publications.

[17] Seidman, I.E. (1991) Interviewing as qualitative research: A guide for researchers in education and the social sciences. New York: Teachers College Press.

[18] Solomon, R.P. (1997) 'Race, role modeling, and representation in teacher education and teaching'. Canadian Journal of Education, 22(4), 395-410.

[19] Vygotsky, L.S. (1978). Mind and Society. Cambridge, MA: Harvard University Press.

[20] Weiler, Kathleen. (1997). Making Cultural Diversity Work. Toronto: Thomson Canada Limited. 